\title{
Health status, health behaviour and healthcare use among migrants in the UK: Evidence from mothers in the Millennium Cohort Study
}

\author{
Hiranthi Jayaweera $^{\mathrm{a}, *}$, Maria A. Quigley ${ }^{\mathrm{b}}$ \\ ${ }^{a}$ ESRC Centre on Migration, Policy and Society (COMPAS), University of Oxford, 58 Banbury Road, OX2 6QS, United Kingdom \\ ${ }^{\mathrm{b}}$ National Perinatal Epidemiology Unit, University of Oxford, Oxford, United Kingdom
}

\section{A R T I C L E I N F O}

\section{Article history:}

Available online 16 June 2010

\section{Keywords:}

UK

Migrants

Ethnicity

Mothers

Epidemiology

Health status

Health behaviour

Healthcare use

\begin{abstract}
A B S T R A C T
The health of migrants in the UK and their access to healthcare is of considerable policy interest. There is evidence of ethnic inequalities in health and access to and use of healthcare but insufficient consideration of the importance of birth abroad and length of residence in the UK. This study examines indicators of health status, behaviour and healthcare use among mothers of infants in the Millennium Cohort Study, according to whether born in the UK or abroad, individual ethnic grouping, and length of residence. Our findings show there are both positive and negative health indicators associated with ethnicity, birth abroad, and length of residence and presenting results on a single factor in isolation could lead to a misinterpretation of associations. For mothers ethnicity has an important relationship with most health indicators independent of country of birth, length of residence and socio-demographic circumstances. Once adjusted for ethnicity and socio-demographic variables, association with birth abroad disappears for most health outcomes suggesting that there may not be an independent migrant penalty in health. There is a linear trend in decreasing health status with increasing length of residence but no independent association between length of residence and healthcare use. This suggests that while there are continuing barriers to good health for migrants in the receiving society as shown in other studies, factors important for one health outcome may not apply to another. Our findings challenge linear acculturation models for migrants' health in showing that a linear trend in improving socio-economic circumstances for mothers in some ethnic groups is not always associated with better health outcomes or changes in health behaviour. Our results point to a need for a comprehensive collection of information and analysis for all categories of migrants for understanding patterns of and factors underlying health and use of healthcare.
\end{abstract}

(c) 2010 Elsevier Ltd. All rights reserved.

\section{Introduction}

The health of migrants in the UK and their access to healthcare is of academic, policy and practitioner interest. There has been a rise in net immigration over the last few decades that has resulted in a greater share of non-UK born people in the total population. NonUK born people made up about $11 \%$ of the total UK population in 2008 (Office for National Statistics, 2009). The diversity of migrants in the UK today in terms of countries of origin, ethnicity, socioeconomic circumstances, religion, legal status and length of residence, has significant implications for their health status and needs, and entitlement and access to healthcare.

This paper examines the relationship of some of these factors with the health of mothers of infants, through analysis of data from

\footnotetext{
* Corresponding author. Tel.: +44 1865274695.

E-mail address: hiranthi.jayaweera@compas.ox.ac.uk (H. Jayaweera).
}

a national population-based study. It adds to previous research on such mothers by throwing light on the association between being a migrant (birth abroad), ethnicity, length of residence in the UK and socio-demographic circumstances, and their health status, health behaviour and healthcare use.

\section{Background}

The health of migrants is a key indicator of 'integration' within receiving societies, alongside employment, education and housing (Spencer \& Cooper, 2006). UK research evidence on the health of migrants, particularly recent migrants, is patchy, with greater focus on minority ethnic groups some of whom are UK born (Piachaud, Bennett, Nazroo, \& Popay, 2009; Fitzpatrick, Jacobson, \& Aspinal, 2005). Ironically, since the early 1990s when ethnic group information collection in the Census began, there has been a reversal of the situation in the 1970 s and 1980 s when mainly only country of 
birth was recorded, such that the emphasis recently has been on providing a complete account of ethnic variations in health data, for example in hospital and primary care data (Richardson \& Mmata, 2007; Warburton, 2008). However, existing evidence does not always include country of birth and date of arrival in the UK.

Not surprisingly, current health policy, which relies on routine and population survey data, primarily focuses on ethnic inequalities. The government's Public Service Agreement (PSA) target to reduce health inequalities focuses on achieving improvements in cross-cutting social determinants of health. The evidence is mainly given by ethnicity, rather than including country of birth and date of arrival for migrants, apart from mortality statistics where only country of birth is recorded (Acheson, 1998; Health Inequalities Unit, 2008). The evidence for ethnic inequalities in health is well documented (Commission for Healthcare Audit and Inspection, 2008; Marmot et al., 2010; Sproston \& Mindell, 2006). However, the literature on ethnic inequalities in health is often separate from evidence and policy concerns about the health of migrants; the latter being focused more specifically upon the association between source country conditions, the trauma of the migration process and issues around entitlement to care and the health of asylum seekers and refugees, or on the prevalence of particular diseases such as Tuberculosis or HIV (Health Protection Agency, 2006; Piachaud et al., 2009).

Our focus in this paper is on mothers of infants (under one year), for whom there is evidence of ethnic inequalities in health. A study in England found that Black and Minority Ethnic (BME) women accessed antenatal care later than White women, and were less likely to report offer and uptake of screening for Down's Syndrome and to feel they were treated with respect by health professionals. Non-UK born BME women compared to UK-born White women were less likely to be offered antenatal classes and reported less access to care options. All and specifically non-UK born, BME women were significantly more likely than White women to report poor health postnatally (Redshaw, Rowe, Hockley, \& Brocklehurst, 2007).

The most recent Confidential Enquiry into Maternal Deaths (CEMD) in the UK shows that in 2003-2005 Black African mothers, followed by Black Caribbean and Middle Eastern mothers, had significantly higher death rates than White mothers. Higher percentages among minority ethnic mothers who died than among White mothers, reported late booking ( $>22$ weeks) or no antenatal care, and in the total number of maternal mortalities, the percentage of mothers who spoke no English was relatively high. Of the 35 Black African mothers who died, 4 were UK citizens, the rest mainly being recent migrants including asylum seekers and refugees. The report notes the rise in numbers of recent migrants among mothers who died since the last confidential enquiry, including for the first time, mothers from EU Accession countries (Lewis, 2007).

A national population study revealed that Black African and Black Caribbean women in the UK had more than double the risk of severe maternal morbidity than White women, a pattern that is similar to ethnic differences in maternal death rates. Non-White women had a significant increased risk of severe morbidity than White women even after adjustment for other factors (Knight, Kurinczuk, Spark, \& Brocklehurst, 2009). This study raised questions about factors associated with ethnic differences in severe maternal morbidities such as differences in access to care. Local and qualitative studies of minority ethnic women in the UK have also highlighted poorer health outcomes and inequalities in access to information and maternity care linked with factors such as lack of English fluency and constrained material circumstances (Jayaweera, D'Souza, \& Garcia, 2005; Katbamna, 2000). There is recognition of gaps in data collection and analysis restricting interpretation of results and a call for more information on mothers' countries of birth, languages spoken, and length of residence for migrants in receiving societies, to gain a fuller understanding of maternal health inequalities (Pollock \& King, 2009).

In the wider UK population, the limited evidence suggests that most migrants have relatively good health but that the health status of some migrants deteriorates after arrival (Johnson, 2006). In some accounts the concept of 'acculturation' - the adoption of norms, values and behaviour in the receiving society - is used to explain changes in migrants' health- for instance, the impact of increased levels of smoking and processed diets on cardio-vascular disease and cancer (Zaman \& Mangtani, 2007). But there is also recognition of theoretical and empirical limitations of using models of acculturation to understand migrants' health (Abraldo-Lanza, Armbrister, Florez, \& Aguirre, 2006; Hunt, Schneider, \& Comer, 2004). Other accounts place greater emphasis on structural barriers to good health and care such as socio-economic deprivation including substandard housingand poor quality food, migrants' lack of knowledge of, access to and uptake of screening and immunisation, and inadequacy and insensitivity in support - including language support given by healthcare providers (Johnson, 2006).

Thus, while there is growing concern about the health of migrants and barriers they face in accessing healthcare, much evidence in national data sets has not yet been extracted for migrants given primary focus on ethnic inequalities in health. The aim of this paper is to examine the relationship between country of birth (born in the UK/born abroad), length of residence in the UK, and ethnicity, and health status, health behaviour and healthcare use, through secondary analysis of a population-based study of mothers of infants. The term 'migrant' is used in this paper in the broadest sense to refer to mothers born outside the UK. The research question addressed is whether there is specifically a migrant penalty or benefit in health for such mothers, taking into account length of residence, ethnic, demographic and socio-economic differences. The results reported in this paper strengthen the evidence base on the health of migrants and their healthcare use in the UK over time, and provide new insights for policy making and service delivery as well as identifying gaps in the evidence base for future research.

\section{Methods}

The Millennium Cohort Study (MCS) is a national longitudinal birth cohort study which follows a sample of children born in the United Kingdom at the beginning of the new millennium (Dex \& Joshi, 2005; Plewis, 2007). Sweep 1 of the study was carried out in 2001-2002 when infants were about 9 months old. The sample included 18,818 infants selected from child benefit records. Families not eligible for universal benefits, such as those with legal statuses that preclude them from access to public funds and services were not eligible for the MCS. Among the excluded are those most likely to face barriers in accessing free healthcare, such as undocumented migrants and failed asylum seekers (Medact, 2007). The sample design was a random two-stage sample by electoral ward with oversampling of families living in the smaller UK countries, in high ethnic minority density wards (electoral wards in England where at least 30\% of residents were from a (Black or Asian) minority ethnic group in the 1991 Census), and in wards in all four UK countries which were in the poorest quarter of the Child Poverty Index. The interview response rate was $85 \%$ for the UK sample (Plewis, 2007). In Sweep 1, 1\% of main interviews were done in a language other than English and 3\% in English and another language (Hansen, 2008).

\section{Participants}

The analyses reported in this paper are based on data collected in Sweep 1 on health and socio-economic circumstances of families. 
Record linkage with birth registration data provided countries of birth of mothers (Hockley et al., 2007). Date of arrival of non-UK born mothers was provided in Sweep 2 when children were three years old, and was ascertained by the question 'When did you come to the UK to live?' We identified 17,258 biological mothers with information on whether born in the UK or abroad. Among 2327 mothers born abroad, that is, anywhere other than in the four UK countries (hereafter, migrant mothers), 489 (21.0\%) had country of birth recorded in Sweep 1 but no date of arrival recorded in Sweep 2. Higher proportions among Bangladeshi and Black African, than other minority ethnic mothers born abroad had no information on date of arrival (see Table 1). In order to assess non-response bias we compared mothers with and without date of arrival. There were no significant differences in general between mothers with and without date of arrival by age or educational qualifications but mothers with no date of arrival were significantly less likely to speak any English at home ( $p$-value $<0.05)$. The analyses of health variables by country of birth included migrant mothers with no date of arrival but they were excluded from analyses by length of residence.

\section{Measures}

We analysed the health status, health behaviour and healthcare use of mothers according to: country of birth; ethnicity; and for migrants, length of residence in the UK. In the survey, ethnic group was self-defined by mothers with reference to 2001 Census categories. We grouped mothers as: White British/Irish, Other White, Indian, Pakistani, Bangladeshi, Black Caribbean and Black African, omitting 'Mixed' and 'Other' categories as these categories were too diverse in ethnic and geographical composition to be meaningful for analysis.

We do not think that in general there are serious implications of combining mothers classifying themselves as White British and as White Irish within the ethnic group classifications used in the MCS particularly taking into account small sample sizes. Other studies based on the MCS have used a similar ethnic grouping - see Hawkins, Lamb, Cole, Law and the Millennium Cohort Study Child Health Group (2008). We have also used a combined White British/Irish category as the baseline in the analysis of migrant mothers because we felt that they could be distinguished from other migrant ethnic group categories historically, and for reasons of small sample size among White Irish.

Among migrant mothers, we calculated length of residence by subtracting year of arrival in the UK from year of first interview (2001 or 2002). We grouped lengths of residence in 3 year bands: $\leq 3$ years (i.e. arrived 1998/1999); 4-6 years; $7-9$ years; $\geq 10$ years. The earliest date of arrival among mothers was 1962 .

In the survey, mothers were asked to describe their general health according to the categories excellent, good, fair and poor. Selfperceived health is considered a reliable measure of health, an important predictor of morbidity and mortality and valid for different ethnic groups (Chandola \& Jenkinson, 2000; Idler \& Benyamini, 1997). We created a binary variable - good (excellent/ good) and poor (fair/poor). Depression was assessed using a (modified) malaise inventory score. Nine of the original 24 items used in studies of general population samples were used in the MCS (Sacker, Quigley, \& Kelly, 2006) and a score of $\geq 4$ was classified as depressed/ anxious (Kelly, Bartley, Schoon, \& Hope, 2004). Indicators of health behaviour were any smoking and alcohol consumption at the time of interview. The healthcare use variables for mothers were: whether they received any antenatal care and whether they attended any antenatal classes. For the latter measure we focused on mothers whose cohort infant was firstborn, as multiparous women in the MCS were less likely to attend antenatal classes (Jayaweera, Joshi, Macfarlane, Hawkes, \& Butler, 2005). The final variable was whether the cohort infant had received any immunisations. All infants born in the UK are routinely offered immunisations in the first 4 months of life (Department of Health, 2008).

The socio-demographic characteristics in the analysis were: mother's age at interview; highest educational qualifications using National Vocational Qualifications (NVQ) equivalence ('higher NVQ 4/5', 'medium - NVQ 3', 'lower - NVQ 1/2', 'overseas qualifications', 'none'); whether cohort infant was first live birth or not (as a proxy measure of parity); employment status ('working/on leave/has worked in the past' and 'never worked'); occupational class - highest of mother or her partner classified by the National Statistics socio-economic classification ('managerial/professional' and 'other'); ward type used for the selection of the sample

Table 1

Country of birth, length of residence in the UK and socio-demographic characteristics of mothers within ethnic groups, 2001-2002.

\begin{tabular}{|c|c|c|c|c|c|c|c|}
\hline & $\begin{array}{l}\text { White British/Irish } \\
(n=14,969)\end{array}$ & $\begin{array}{l}\text { Other White } \\
(n=342)\end{array}$ & $\begin{array}{l}\text { Indian } \\
(n=464)\end{array}$ & $\begin{array}{l}\text { Pakistani } \\
(n=858)\end{array}$ & $\begin{array}{l}\text { Bangladeshi } \\
(n=354)\end{array}$ & $\begin{array}{l}\text { Black Caribbean } \\
(n=260)\end{array}$ & $\begin{array}{l}\text { Black African } \\
(n=367)\end{array}$ \\
\hline \multicolumn{8}{|c|}{ Country of birth and length of residence in the UK } \\
\hline Born UK & $97.4 \%$ & $14.1 \%$ & $50.0 \%$ & $40.5 \%$ & $9.9 \%$ & $81.3 \%$ & $23.7 \%$ \\
\hline Born abroad & $2.6 \%$ & $86.0 \%$ & $50.1 \%$ & $59.5 \%$ & $90.1 \%$ & $18.7 \%$ & $76.3 \%$ \\
\hline$\geq 10$ years & $1.8 \%$ & $29.2 \%$ & $19.7 \%$ & $24.4 \%$ & $45.1 \%$ & $8.4 \%$ & $25.9 \%$ \\
\hline $7-9$ years & $0.1 \%$ & $11.6 \%$ & $7.5 \%$ & $6.6 \%$ & $6.5 \%$ & $2.2 \%$ & $10.5 \%$ \\
\hline $4-6$ years & $0.1 \%$ & $17.2 \%$ & $8.5 \%$ & $8.1 \%$ & $9.0 \%$ & $2.7 \%$ & $10.6 \%$ \\
\hline$\leq 3$ years & $0.1 \%$ & $11.7 \%$ & $7.5 \%$ & $9.9 \%$ & $8.0 \%$ & $1.4 \%$ & $6.6 \%$ \\
\hline No date of arrival & $0.5 \%$ & $16.2 \%$ & $6.9 \%$ & $10.4 \%$ & $21.5 \%$ & $4.0 \%$ & $22.7 \%$ \\
\hline \multicolumn{8}{|l|}{ Socio-demographic characteristics } \\
\hline Highest qualification (NVQ4/5) & $32.7 \%$ & $52.5 \%$ & $40.6 \%$ & $12.6 \%$ & $9.6 \%$ & $32.7 \%$ & $42.7 \%$ \\
\hline $\begin{array}{l}\text { Managerial/professional } \\
\text { occupation }^{\mathrm{a}}\end{array}$ & $46.0 \%$ & $65.9 \%$ & $43.8 \%$ & $16.2 \%$ & $17.0 \%$ & $35.3 \%$ & $29.6 \%$ \\
\hline Any English spoken at home ${ }^{\mathrm{b}}$ & $99.8 \%$ & $87.8 \%$ & $87.8 \%$ & $75.0 \%$ & $65.4 \%$ & $99.8 \%$ & $86.1 \%$ \\
\hline Never in labour market & $4.2 \%$ & $7.9 \%$ & $15.9 \%$ & $44.3 \%$ & $57.6 \%$ & $7.0 \%$ & $27.1 \%$ \\
\hline Lone parent & $14.2 \%$ & $6.7 \%$ & $4.3 \%$ & $7.0 \%$ & $5.5 \%$ & $47.8 \%$ & $39.0 \%$ \\
\hline Religion - None & $50.5 \%$ & $35.1 \%$ & $7.8 \%$ & $0.9 \%$ & $1.5 \%$ & $30.4 \%$ & $4.2 \%$ \\
\hline Christian/Catholic & $48.4 \%$ & $51.2 \%$ & $3.4 \%$ & $0.1 \%$ & $0.5 \%$ & $63.5 \%$ & $65.2 \%$ \\
\hline Muslim & $0.2 \%$ & $7.8 \%$ & $15.2 \%$ & $98.2 \%$ & $95.5 \%$ & $2.8 \%$ & $28.7 \%$ \\
\hline Hindu/Sikh & $0.0 \%$ & $0.1 \%$ & $72.5 \%$ & $0.6 \%$ & $2.4 \%$ & $0.0 \%$ & $0.0 \%$ \\
\hline Other & $1.0 \%$ & $5.9 \%$ & $1.1 \%$ & $0.2 \%$ & $0.2 \%$ & $3.4 \%$ & $2.0 \%$ \\
\hline Residence in ethnic wards & $1.1 \%$ & $7.0 \%$ & $36.5 \%$ & $46.8 \%$ & $70.8 \%$ & $29.0 \%$ & $32.7 \%$ \\
\hline
\end{tabular}

${ }^{\text {a }}$ Highest of mother or partner.

b Includes: only English and English and other languages. 
('ethnic', 'disadvantaged', 'advantaged'); language usually spoken at home ('only English'/'English and other languages', and 'only other languages'); lone parent or not at interview; and religion ('none', 'Christian/Catholic', 'Muslim', 'Hindu/Sikh', 'Other').

\section{Statistical analyses}

All analyses were carried out using weights and survey commands to take into account the clustered survey design. Hence, all proportions, means and odds ratios presented are weighted using sweep 1 weights; these allow for oversampling and nonresponse at sweep1. All confidence intervals and $p$-values account for clustering. Logistic regression analyses were carried out i) to examine the relationships that country of birth, and ethnicity, had with indicators of health status, health behaviour and access to healthcare in all mothers, and ii) to examine the relationships that length of residence in the UK and ethnicity had with the same indicators in migrant mothers only. The modelling strategy employed was to measure the independent associations between country of birth and ethnicity and the study outcomes, after allowing for potential confounding variables. Hence, "country of birth" and "ethnicity" remained in all models, irrespective of their association with the outcome. While country of birth and ethnicity were strongly associated with each other and with some of the confounding variables (Table 1 ), there were always enough individuals in every combination of categories to estimate odds ratios and standard errors precisely. The only exception was the strong association between ethnicity and alcohol, which was addressed by excluding particular ethnic groups from the model. Adjustment was made for any of the socio-demographic variables described above which were significantly ( $p$-value $<0.05$ ) associated with the outcome after adjusting for all other variables in the model, that is, they significantly improved the fit of the model. In the analysis of length of residence in the UK, a test for linear trend was performed to determine whether the outcome changed as length of residence increased. Here, being resident for $\leq 3$ years was used as the baseline and a linear trend odds ratio above one indicated an increase in the outcome as length of residence increased. In analyses by ethnic group for all mothers and for migrant mothers separately, the self-classified White British/Irish category was used as the baseline. This category includes mothers born in Germany, Australia as well as the Irish Republic. The statistical analysis was conducted using STATA Version 9.2.

\section{Results}

Migration patterns, ethnicity and socio-demographic circumstances

Analysis is based on 17, 258 mothers of whom 2327 were born outside the UK.

Table 1 shows country of birth, and for migrant mothers, length of residence, within each ethnic group. Different patterns in each group reflect different migration trajectories. Black Caribbean mothers are mainly born in the UK or established migrants, while Black African, Bangladeshi and Other White mothers are largely migrant populations with substantial proportions of long term residents in the UK but also with fairly considerable proportions of more recent migrants. Indian mothers are the most established South Asian group.

Table 1 also shows patterns of socio-demographic indicators by ethnic group. There are marked ethnic differences. Among ethnic groups with large proportions of migrants, Other Whites and Indians have the highest educational and occupational levels, while Pakistanis and Bangladeshis have the lowest. The proportion able to speak English fairly fluently is high overall among minority ethnic groups, as defined by whether English is spoken in the home. There are large proportions of lone parents among both Black Caribbean and Black African mothers. In both groups these are largely single, never married women, although among Black African migrant mothers there are also separated and married mothers living as lone parents. Most Pakistani and Bangladeshi mothers are of Muslim faith, but so are $29 \%$ of Black African mothers. However, our analyses for individual ethnic groups show that there are differences within ethnic groups in some indicators according to country of birth. For instance in all minority ethnic groups there are lower proportions of mothers born abroad with qualifications equivalent to NVQ 4/5 and with English fluency ( $p$-value $<0.05$, data not shown).

Fig. 1 based on migrant mothers with date of arrival information shows a linear trend in some socio-economic circumstances according to length of residence. Overall, as mothers live in the UK for longer, they have higher educational, occupational and English fluency levels, are less likely to be economically inactive and to live in areas with high minority ethnic density. This is also apparent for individual ethnic groups for some indicators. For example there is a significant trend of increasing English fluency according to length of residence for Indian, Bangladeshi, Black African and Other White mothers and decreasing economic inactivity by length of residence for migrants in all minority ethnic groups ( $p$-value $<0.05$ for linear trend test, data not shown). These results suggest that considering country of birth and length of residence in analysing ethnic differences in socio-demographic circumstances of mothers provides valuable information. We next consider what implications country of birth, length of residence, ethnicity and socio-demographic patterns and trends have for mothers' health indicators.

\section{Country of birth, length of residence, ethnicity and health}

Table 2 examines indicators of health status, health behaviour and access to healthcare by country of birth and by ethnic group for the entire sample including migrants with no date of arrival. Table 3 examines these health indicators for migrant mothers with a date of arrival, by length of residence and ethnic group. All significant relationships have been highlighted in bold.

\section{Poor self-perceived general health}

Results in Table 2 show that migrant mothers and most minority ethnic mothers are significantly more likely to say that they have poor general health than, respectively, UK born mothers and those classifying themselves as White British/Irish. After adjusting for ethnicity and socio-demographic variables, birth abroad is no longer significantly associated with poor general health. But after

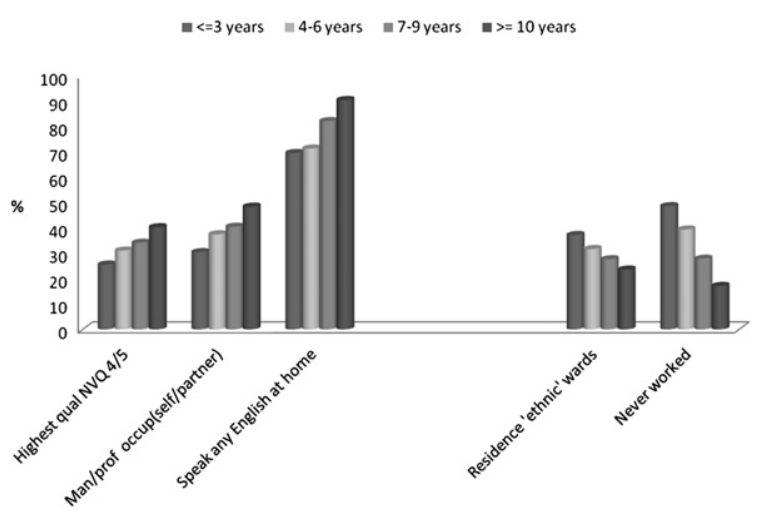

Fig. 1. Socio-economic circumstances by length of residence among migrant mothers, 2001-2002. $p$-value for linear trend test $<0.05$. 
Table 2

Indicators of health status, health behaviour and access to healthcare of mothers by country of birth ${ }^{\mathrm{b}}$ and ethnic group, 2001-2002.

\begin{tabular}{|c|c|c|c|c|c|c|c|}
\hline & $\begin{array}{l}\text { Poor self-perceived } \\
\text { general health }\end{array}$ & $\begin{array}{l}\text { Malaise Inventory } \\
\text { Score for depression }\end{array}$ & Current smoking & $\begin{array}{l}\text { Current alcohol } \\
\text { consumption }^{\mathrm{c}}\end{array}$ & No antenatal care & $\begin{array}{l}\text { No antenatal classes } \\
\text { if first infant }\end{array}$ & $\begin{array}{l}\text { No immunisations } \\
\text { for infant }\end{array}$ \\
\hline \multicolumn{8}{|l|}{ Country of birth $(n=17,258)$} \\
\hline Born UK' $(14,931)$ & $16.3 \%$ & $13.4 \%$ & $30.8 \%$ & $85.4 \%$ & $2.4 \%$ & $30.6 \%$ & $1.2 \%$ \\
\hline Born abroad ${ }^{b}(2327)$ & $19.2 \%$ & $15.0 \%$ & $11.9 \%$ & $45.2 \%$ & $7.1 \%$ & $37.5 \%$ & $1.9 \%$ \\
\hline Unadjusted OR & $1.23(1.09-1.38)$ & $1.14(0.99-1.31)$ & $0.30(0.25-0.37)$ & $0.14(0.12-0.17)$ & $3.05(2.22-4.21)$ & $1.36(1.11-1.67)$ & $1.62(1.11-2.36)$ \\
\hline Adjusted OR & $0.82(0.64-1.03)^{d}$ & $0.79(0.62-1.00)^{d}$ & $0.76(0.59-0.98)^{\mathrm{e}}$ & $0.92(0.69-1.23)^{\mathrm{f}}$ & $1.39(0.87-2.23)^{\mathrm{f}}$ & $0.75(0.53-1.06)^{g}$ & $1.45(0.84-2.50)^{\mathrm{h}}$ \\
\hline \multicolumn{8}{|l|}{ Ethnic group $(n=17,611)$} \\
\hline White British/Irish $(14,969)$ & $15.7 \%$ & $13.0 \%$ & $31.4 \%$ & $87.3 \%$ & $2.4 \%$ & $29.6 \%$ & $1.2 \%$ \\
\hline Other White (342) & $13.6 \%$ & $16.1 \%$ & $20.3 \%$ & $74.4 \%$ & $3.7 \%$ & $23.2 \%$ & $2.2 \%$ \\
\hline Indian (464) & $21.9 \%$ & $22.2 \%$ & $6.2 \%$ & $33.1 \%$ & $5.6 \%$ & $37.8 \%$ & $0.7 \%$ \\
\hline Pakistani (858) & $25.9 \%$ & $23.4 \%$ & $3.8 \%$ & $1.5 \%$ & $10.5 \%$ & $77.6 \%$ & $2.0 \%$ \\
\hline Bangladeshi (354) & $21.1 \%$ & $16.3 \%$ & $1.7 \%$ & $0.9 \%$ & $11.6 \%$ & $78.8 \%$ & $1.0 \%$ \\
\hline Black Caribbean (260) & $29.4 \%$ & $16.4 \%$ & $34.5 \%$ & $72.3 \%$ & $2.1 \%$ & $42.8 \%$ & $4.7 \%$ \\
\hline Black African (367) & $22.3 \%$ & $12.4 \%$ & $6.6 \%$ & $38.7 \%$ & $4.6 \%$ & $48.0 \%$ & $1.4 \%$ \\
\hline Unadjusted OR White British/Irish & 1 & 1 & 1 & 1 & 1 & 1 & 1 \\
\hline Other White & $0.85(0.61-1.18)$ & $1.28(0.97-1.69)$ & $0.56(0.40-0.76)$ & $0.42(0.31-0.57)$ & $1.55(0.79-3.06)$ & $0.72(0.49-1.05)$ & $1.82(0.81-4.09)$ \\
\hline Indian & $1.51(1.11-2.06)$ & $1.91(1.37-2.65)$ & $0.15(0.09-0.23)$ & $0.07(0.05-0.10)$ & $2.41(1.56-3.74)$ & $1.45(0.97-2.15)$ & $0.55(0.18-1.67)$ \\
\hline Pakistani & $1.89(1.53-2.32)$ & $2.04(1.60-2.60)$ & $0.09(0.05-0.14)$ & - & $4.80(3.11-7.39)$ & $8.26(5.39-12.67)$ & $1.69(1.05-2.73)$ \\
\hline Bangladeshi & $1.44(1.01-2.05)$ & $1.30(0.94-1.79)$ & $0.04(0.02-0.08)$ & - & $5.33(2.40-11.87)$ & $8.83(5.28-14.76)$ & $0.87(0.35-2.14)$ \\
\hline Black Caribbean & $2.25(1.67-3.01)$ & $1.31(0.94-1.83)$ & $1.15(0.84-1.57)$ & $0.38(0.27-0.53)$ & $0.89(0.37-2.18)$ & $1.78(1.13-2.81)$ & $4.08(2.21-7.54)$ \\
\hline Black African & $1.55(1.14-2.10)$ & $0.95(0.62-1.46)$ & $0.15(0.09-0.26)$ & $0.09(0.07-0.13)$ & $1.95(1.11-3.43)$ & $2.20(1.57-3.09)$ & $1.15(0.49-2.70)$ \\
\hline Adjusted OR White British/Irish & $1^{\mathrm{d}}$ & $1^{\mathrm{d}}$ & $1^{\mathrm{e}}$ & $1^{\mathrm{f}}$ & $1^{g}$ & $1^{\mathrm{h}}$ & $1^{\mathrm{i}}$ \\
\hline Other White & $1.32(0.90-1.94)$ & $1.78(1.30-2.44)$ & $1.31(0.85-2.00)$ & $0.59(0.36-0.97)$ & $1.55(0.73-3.28)$ & $1.32(0.77-2.29)$ & $1.08(0.51-2.29)$ \\
\hline Indian & $1.75(1.14-2.70)$ & $2.28(1.47-3.53)$ & $0.56(0.19-1.66)$ & $0.16(0.09-0.28)$ & $1.24(0.50-3.08)$ & $2.48(0.78-7.88)$ & $0.67(0.15-2.96)$ \\
\hline Pakistani & $1.65(1.16-2.33)$ & $1.94(1.37-2.74)$ & $0.31(0.15-0.66)$ & - & $1.74(0.82-3.72)$ & $3.71(1.95-7.06)$ & $0.71(0.16-3.19)$ \\
\hline Bangladeshi & $1.42(0.91-2.23)$ & $1.37(0.85-2.23)$ & $0.15(0.05-0.50)$ & - & $1.37(0.51-3.65)$ & $4.72(1.83-12.20)$ & $0.54(0.11-2.73)$ \\
\hline Black Caribbean & $2.15(1.45-3.18)$ & $1.20(0.86-1.68)$ & $1.01(0.71-1.45)$ & $0.48(0.32-0.73)$ & $0.52(0.20-1.31)$ & $1.24(0.58-2.64)$ & $2.21(1.14-4.26)$ \\
\hline Black African & $1.60(1.01-2.54)$ & $1.04(0.66-1.65)$ & $0.21(0.11-0.41)$ & $0.19(0.11-0.31)$ & $1.00(0.49-2.07)$ & $1.68(0.96-2.94)$ & $0.45(0.13-1.48)$ \\
\hline
\end{tabular}

a Baseline group.

$(1.01-2.54)$

b Includes migrants with no date of arrival recorded.

c Pakistani and Bangladeshi ethnic groups not included in unadjusted and adjusted analyses because alcohol rates close to zero.

${ }^{d}$ Adjusted for: ethnic group/country of birth, parity, age, education, occupational class, ward type, lone parent.

e Adjusted for: ethnic group/country of birth, age, religion, parity, education, occupational class, ward type, lone parent, language.

${ }^{\mathrm{f}}$ Adjusted for: ethnic group/country of birth, age, religion, parity, education, occupational class, ward type, employment status, language.

${ }^{g}$ Adjusted for: ethnic group/country of birth, age, religion, education, occupational class, ward type, employment status.

${ }^{\mathrm{h}}$ Adjusted for: ethnic group/country of birth, age, religion, education, occupational class, ward type, lone parent, language.

i Adjusted for ethnic group/country of birth, age, religion, parity, education, ward type, lone parent. 
Table 3

Indicators of health status, health behaviour and access to healthcare of migrant mothers by length of residence in the UK and ethnic group ${ }^{\mathrm{c}}, 2001-2002$.

\begin{tabular}{|c|c|c|c|c|c|c|c|}
\hline & $\begin{array}{l}\text { Poor self-perceived } \\
\text { general health }\end{array}$ & $\begin{array}{l}\text { Malaise Inventory } \\
\text { Score for depression }\end{array}$ & Current smoking & $\begin{array}{l}\text { Current alcohol } \\
\text { consumption }^{\mathrm{d}}\end{array}$ & No antenatal care & $\begin{array}{l}\text { No antenatal classes } \\
\text { if first infant }\end{array}$ & $\begin{array}{l}\text { No immunisations } \\
\text { for infant }\end{array}$ \\
\hline \multicolumn{8}{|c|}{ Length of residence in the UK $(n=1838)$} \\
\hline$\geq 10$ years $(963)$ & $20.6 \%$ & $16.1 \%$ & $12.8 \%$ & $55.5 \%$ & $6.6 \%$ & $24.8 \%$ & $2.0 \%$ \\
\hline $7-9$ years $(251)$ & $20.7 \%$ & $13.1 \%$ & $9.6 \%$ & $43.7 \%$ & $8.7 \%$ & $25.4 \%$ & $1.8 \%$ \\
\hline $4-6$ years $(323)$ & $21.3 \%$ & $20.0 \%$ & $9.0 \%$ & $36.0 \%$ & $8.5 \%$ & $38.4 \%$ & $1.4 \%$ \\
\hline$\leq 3$ years $^{\mathrm{a}}(301)$ & $14.4 \%$ & $11.5 \%$ & $7.7 \%$ & $28.4 \%$ & $7.7 \%$ & $51.7 \%$ & $0.8 \%$ \\
\hline Unadjusted OR & $1.09(0.98-1.22)$ & $1.04(0.90-1.20)$ & $1.21(1.02-1.45)$ & $1.48(1.31-1.66)$ & $0.92(0.80-1.07)$ & $0.68(0.55-0.83)$ & $1.28(0.87-1.87)$ \\
\hline Adjusted $\mathrm{OR}^{\mathrm{b}}$ & $1.24(1.06-1.44)^{\mathrm{e}}$ & $1.28(1.07-1.53)^{\mathrm{e}}$ & $1.09(0.83-1.43)^{\mathrm{f}}$ & $1.08(0.85-1.35)^{\mathrm{g}}$ & $1.25(0.98-1.61)^{\mathrm{e}}$ & $0.92(0.66-1.27)^{\mathrm{h}}$ & $1.15(0.77-1.72)^{\mathrm{i}}$ \\
\hline \multicolumn{8}{|l|}{ Ethnic group $^{c}(n=1590)$} \\
\hline White British/Irish (316) & $14.1 \%$ & $12.7 \%$ & $22.3 \%$ & $90.0 \%$ & $2.7 \%$ & $15.3 \%$ & $1.9 \%$ \\
\hline Other White (225) & $13.2 \%$ & $15.3 \%$ & $18.5 \%$ & $76.8 \%$ & $2.9 \%$ & $20.3 \%$ & $2.4 \%$ \\
\hline Indian (199) & $18.9 \%$ & $18.9 \%$ & $2.1 \%$ & $24.8 \%$ & $7.0 \%$ & $33.8 \%$ & $1.1 \%$ \\
\hline Pakistani (397) & $22.7 \%$ & $21.2 \%$ & $1.7 \%$ & $1.0 \%$ & $13.4 \%$ & $77.4 \%$ & $2.0 \%$ \\
\hline Bangladeshi (222) & $21.7 \%$ & $16.7 \%$ & $0.4 \%$ & $0.4 \%$ & $11.8 \%$ & $76.5 \%$ & $1.1 \%$ \\
\hline Black Caribbean (39) & $31.1 \%$ & $30.4 \%$ & $25.2 \%$ & $70.2 \%$ & $6.8 \%$ & $70.1 \%$ & $8.1 \%$ \\
\hline Black African (192) & $30.6 \%$ & $14.3 \%$ & $4.7 \%$ & $37.7 \%$ & $6.1 \%$ & $34.8 \%$ & $1.4 \%$ \\
\hline Unadjusted OR White British/Irish & 1 & 1 & 1 & 1 & 1 & 1 & 1 \\
\hline Other White & $0.93(0.52-1.64)$ & $1.24(0.75-2.03)$ & $0.79(0.47-1.32)$ & $0.37(0.22-0.62)$ & $1.07(0.36-3.21)$ & $1.41(0.68-2.91)$ & $1.26(0.43-3.72)$ \\
\hline Indian & $1.42(0.73-2.76)$ & $1.60(0.88-2.89)$ & $0.07(0.03-0.21)$ & $0.04(0.02-0.07)$ & $2.69(0.88-8.18)$ & $2.84(1.13-7.14)$ & $0.54(0.09-3.32)$ \\
\hline Pakistani & $1.80(1.10-2.94)$ & $1.85(1.18-2.91)$ & $0.06(0.02-0.15)$ & - & $5.53(2.24-13.64)$ & $19.01(8.54-42.30)$ & $1.01(0.31-3.28)$ \\
\hline Bangladeshi & $1.70(0.96-3.00)$ & $1.38(0.78-2.45)$ & $0.01(0.00-0.07)$ & _- & $4.77(1.42-15.97)$ & $18.11(6.79-48.32)$ & $0.55(0.16-1.85)$ \\
\hline Black Caribbean & $2.75(1.09-6.92)$ & $3.00(1.19-7.57)$ & $1.17(0.48-2.86)$ & $0.26(0.10-0.67)$ & $2.62(0.51-13.34)$ & $13.00(3.05-55.32)$ & $4.48(0.78-25.68)$ \\
\hline Black African & $2.69(1.57-4.61)$ & $1.15(0.54-2.43)$ & $0.17(0.07-0.42)$ & $0.07(0.04-0.12)$ & $2.34(0.82-6.67)$ & $2.96(1.36-6.40)$ & $0.72(0.15-3.37)$ \\
\hline Adjusted OR White British/Irish & $1^{\mathrm{e}}$ & $1^{\mathrm{e}}(\mathrm{lol}-2.0)$ & 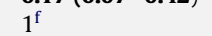 & $1^{g}(0.0)(10)$ & $1^{\mathrm{e}}$ & $1^{\mathrm{h}}$ & 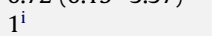 \\
\hline Other White & $1.13(0.64-2.00)$ & $1.73(1.05-2.84)$ & $1.17(0.68-2.03)$ & $0.58(0.29-1.14)$ & $1.36(0.47-4.00)$ & $1.16(0.45-2.98)$ & $1.21(0.40-3.68)$ \\
\hline Indian & $1.57(0.80-3.07)$ & $1.85(1.00-3.44)$ & $0.14(0.05-0.46)$ & $0.05(0.02-0.14)$ & $2.98(0.91-9.81)$ & $5.91(0.79-44.15)$ & $0.47(0.09-2.51)$ \\
\hline Pakistani & $1.72(1.00-2.97)$ & $1.66(1.00-2.74)$ & $0.17(0.04-0.82)$ & - & $4.18(1.65-10.60)$ & $7.00(1.90-25.78)$ & $0.87(0.24-3.21)$ \\
\hline Bangladeshi & $1.50(0.82-2.75)$ & $1.10(0.58-2.10)$ & $0.03(0.00-0.24)$ & - & $3.55(0.97-13.03)$ & $8.28(2.06-33.27)$ & $0.55(0.16-1.90)$ \\
\hline Black Caribbean & $2.93(1.19-7.24)$ & $3.00(1.09-8.28)$ & $0.54(0.23-1.24)$ & $0.62(0.26-1.48)$ & $2.47(0.42-14.41)$ & $3.23(0.71-14.62)$ & $3.64(0.72-18.53)$ \\
\hline Black African & $2.87(1.65-5.00)$ & $1.32(0.65-2.68)$ & $0.13(0.04-0.42)$ & $0.27(0.15-0.49)$ & $2.34(0.83-6.64)$ & $0.68(0.21-2.19)$ & $0.57(0.12-2.67)$ \\
\hline
\end{tabular}

a Baseline group.

$\mathrm{b}$ Length of residence ORs computed using a linear trend analysis.

c excludes those born in the UK and migrants with no date of arrival recorded.

Pakistani and Bangladeshi ethnic groups not included in unadjusted and adjusted analyses because alcohol rates close to zero.

e adjusted for: length of residence/ethnic group, age, education.

f adjusted for: length of residence/ethnic group, age, education, employment status, lone parent, ward type, religion.

$\mathrm{g}$ adjusted for: length of residence/ethnic group, age, education, employment status, occupational class, language, ward type, religion.

h adjusted for: length of residence/ethnic group, age, education, ward type, lone parent, religion.

adjusted for length of residence/ethnicity, age, education, parity. 
adjusting for country of birth and socio-demographic variables, Indian, Pakistani, Black Caribbean and Black African mothers are significantly more likely to report poor general health. This suggests that country of birth is less important than ethnicity as a factor associated with self-perceived health. Among migrant mothers, however, in the adjusted analysis both ethnicity and length of residence in the UK are significantly associated with poor general health (Table 3). There is a significant linear trend of poor general health with increasing length of residence (adjusted OR = 1.24, 95\% CI: 1.06-1.44, Table 3). Pakistani, Black Caribbean and Black African migrant mothers are significantly more likely to report poor health compared to White British/Irish migrant mothers after adjusting for socio-demographic variables and length of residence in the UK.

\section{Malaise inventory score for depression}

In the adjusted analysis, mothers born abroad are less likely to be depressed than UK born mothers, whereas mothers in Other White, Indian and Pakistani ethnic groups are significantly more likely to be depressed than White British/Irish mothers irrespective of country of birth and demographic and socio-economic differences (Table 2). The adjusted analysis of migrant mothers show a significant linear trend of increasing depression with length of residence in the $\mathrm{UK}$ (adjusted $\mathrm{OR}=1.28,95 \% \mathrm{CI}$ : $1.07-1.53$, Table 3 ) and more depression among mothers in Other White, Indian, Pakistani and Black Caribbean ethnic groups compared with White British/Irish migrant mothers. These results suggest that ethnicity may be important for predicting depression in mothers including those who are migrants, and there is an independent association between birth abroad and being less depressed, and between length of residence and increasing depression.

\section{Smoking and alcohol consumption}

Both migrant and minority ethnic mothers (except Black Caribbeans regarding smoking) are significantly less likely to smoke or drink alcohol than those who are UK born and those who are White British/Irish respectively (Table 2). Of note are the very low rates of both smoking and alcohol consumption among Pakistani and Bangladeshi mothers. The lower rates of smoking in migrant mothers and in mothers who are Pakistani, Bangladeshi or Black African remain significant in the adjusted analysis suggesting that, as predictors, birth abroad and ethnicity are independent of each other and of other socio-demographic variables. Among migrant mothers, all ethnic groups except Other White and Black Caribbean categories are significantly less likely to smoke compared with White British/ Irish migrants, but there is no independent association between length of residence and smoking (Table 3). Owing to extremely low rates of alcohol consumption among Pakistani and Bangladeshi mothers, these groups were omitted from logistic regression models for alcohol. In the adjusted analysis birth abroad is not significantly associated with lower alcohol consumption whereas ethnic group remains significant even after excluding Pakistanis and Bangladeshis (Table 2). Among migrant mothers, the adjusted analysis suggests that Indians and Black Africans have significantly lower rates of alcohol consumption compared with White British/Irish, but there is no independent association between length of residence and alcohol consumption (Table 3).

\section{Antenatal care, antenatal classes and infant immunisations}

In unadjusted analyses, migrant and most minority ethnic mothers are significantly less likely to have antenatal care or attend antenatal classes (Table 2). Of note are relatively high rates of reporting no antenatal care among Pakistani (10.5\%) and Bangladeshi (11.6\%) mothers. However, after adjustment for socio-demographic factors, neither country of birth nor ethnic group is significantly associated with antenatal care. The strongest predictors of reporting no antenatal care are younger maternal age, lower or no educational qualifications, never having worked, lower occupational class, and living in a high ethnic minority density ward. In the adjusted analysis of migrants, Pakistani mothers are significantly less likely to have antenatal care compared with White British/Irish mothers, but there is no independent association between length of residence in the UK and antenatal care (Table 3).

In adjusted analysis of mothers whose infant was their firstborn, the relationship between country of birth and antenatal class attendance is not statistically significant whereas Pakistanis and Bangladeshis are significantly less likely to attend antenatal classes. Among migrant mothers, most ethnic minority groups are less likely to attend antenatal classes compared with White British/Irish migrants but attendance increases sharply with length of residence (Table 3 ). In adjusted analysis however, length of residence has a much weaker association with antenatal class attendance than does ethnicity; most notably, migrant Pakistani and Bangladeshi mothers are much less likely to attend classes compared with White British/Irish migrant mothers.

In the unadjusted analysis migrant mothers are significantly more likely to have received no immunisations for their cohort infant. Infants of Pakistani and Black Caribbean mothers are also significantly more likely to have no immunisations, with particularly high rates of non-uptake among Black Caribbeans (4.7\%). In adjusted analysis however, country of birth is no longer significant, but ethnicity remains significant for Black Caribbean mothers. Among migrant mothers, neither length of residence nor ethnicity is significantly associated with receiving immunisations in both unadjusted and adjusted analysis. While again, infants of migrant Black Caribbean mothers show high rates of non-uptake (8.1\%) the very small numbers of migrants among Black Caribbean mothers in the sample $(n=39)$ suggests cautious interpretation of these results.

\section{Discussion}

For mothers in this study ethnicity appears to be significantly associated with most health indicators, independent of country of birth, length of residence, and demographic and socio-economic circumstances. This is so for the entire sample (UK born and born abroad) and migrants separately. Mothers particularly in nonWhite minority ethnic groups are more likely than White British/ Irish mothers to perceive that their health is poor, to feel more depressed, and to not access antenatal classes. However, they are less likely to smoke or consume alcohol. The independent association with ethnicity is less strong for antenatal care and immunisations. The high percentages of Pakistani and Bangladeshi mothers with no antenatal care appear to be related to their relatively poor socio-economic circumstances compared to mothers in other ethnic groups as seen in Table 1. The possible existence of other barriers - information, transport, interpreting, care provider and/ or family support - which have been identified in accounts of maternal and child healthcare access and uptake, need to be recognised (Jayaweera, D'Souza, et al., 2005; Katbamna, 2000). So while ethnic differences are important for differences in health indicators, other differences that exist between ethnic groups may be associated with some health inequalities. Our research, by comparing individual ethnic groups in multivariate analyses, supports and advances findings of previous studies of mothers of infants based on smaller scale local studies or focused on broader ethnic categories or White/non-White dichotomies in populationbased studies (Knight et al., 2009; Redshaw et al., 2007). 
Analysis of country of birth shows that migrant mothers are not a homogenous group; there are ethnic, length of residence, and socio-demographic variations. In unadjusted analyses migrant mothers appear to have worse health outcomes than UK born mothers, such as higher proportions with poor health and no healthcare use, but when adjusted for ethnicity and socio-demographic characteristics the association with country of birth disappears for most health outcomes. This suggests that it is not possible to say that there is a direct migrant penalty in health for mothers in this study without considering other differences among migrants that may be associated with health. However, there is an independent association of birth abroad with smoking and, to a lesser extent, with depression among mothers, with lower proportions relating to both indicators, suggesting the existence of a migrant benefit in some areas of health.

The relationship between length of residence of migrants and health outcomes and health behaviour is a relatively underresearched area especially when considered in conjunction with ethnic differences. Our results showed a complex picture. Of particular concern is our finding that there is a linear trend of increasing proportions of mothers reporting poor general health and depression with increasing length of residence after adjustment for ethnicity and socio-demographic variables, while in use of antenatal care, antenatal classes and infant immunisations there is no independent association with length of residence. Other studies have shown the existence of barriers to good health and healthcare use after arrival in the UK which relate closely to socio-economic deprivation experienced by many migrants in receiving societies (Johnson, 2006). Our findings for mothers support such evidence, particularly in healthcare use among migrants where factors other than length of residence may play a part. However, our findings also suggest that factors important for one health outcome may not be as important for another, as the independent association between length of residence and poor general health and depression shows.

It is interesting that ethnicity is more important as a predictor of smoking and alcohol consumption among migrant mothers, than is length of residence. Another MCS study (Hawkins et al., 2008) as well as studies in the United States (Harley \& Eskenazi, 2006) have used length of residence as a measure of 'acculturation' of migrants in adopting health behaviours characteristic of the majority population in the perinatal period. These include increased levels of smoking and alcohol consumption in pregnancy. Our findings among migrant mothers at around 9 months after birth show that while the linear trend of increasing smoking and alcohol consumption according to length of residence disappears after adjusting for ethnicity and socio-demographic variables, lower rates of smoking and alcohol consumption prevail among many minority ethnic groups even after adjusting for length of residence and socio-demographic circumstances.

Our results highlight the difficulties of disentangling the significance of length of residence from that of ethnicity and of socio-demographic circumstances and point to the importance of studying changes in migrants' health over time in a multi-faceted way. It is also important to consider the relationship between changes in socio-economic circumstances according to length of residence (Fig. 1) and changes in health status, health behaviour and healthcare use. Among migrant mothers a linear trend in improving socio-economic circumstances with length of residence is not always associated with better health outcomes or changes in health behaviour. Such findings call into question the use of simple linear models of 'acculturation' to understand changes in health of migrants (Abraldo-Lanza et al., 2006).

Limitations of the study include lower survey response rate in 'ethnic wards' and missing date of arrival for around one fifth of migrant mothers, both of which may lead to bias or affect the generalisability of the results. Information on smoking and alcohol consumption patterns were based on mothers' self -report and may underestimate actual levels (Walsh, Redman, \& Adamson, 1996). We could not contribute to other evidence that chewing tobacco products prevails among Bangladeshi women who generally report low levels of smoking (Sproston \& Mindell, 2006), as there were no relevant questions in the MCS. The ethnic category 'Black African' among mothers masks diversity in religion (Table 1) and country of origin; among Black African mothers with country of birth information around 20\% were born in Somalia, 15\% in Nigeria and $12 \%$ in Ghana. Health evidence for Black Africans as an ethnic category may hide differences in such a diverse sample and therefore it is important to collect information for a larger number of mothers to enable more accurate analyses. This argument also applies to mothers in the Other White category.

\section{Implications for research, policy and practice}

Our findings on the health status, health behaviour, and healthcare use among mothers of infants in this paper suggest there are positive and negative health indicators associated with ethnicity, country of birth, and length of residence in the UK, and that it is difficult to disentangle these relationships. Presenting results on only one of these factors - i.e. ethnicity versus country of birth versus length of residence - could lead to misinterpretation of associations and thereby wrong conclusions. Future studies and administrative data should collect and analyse information on ethnicity, country of birth and length of residence in addition to relevant socio-demographic and lifestyle factors. Further, we were not able to consider if the relatively high rates of no antenatal care among Pakistani and Bangladeshi mothers were linked with barriers to antenatal care use within source countries. Future research should collect data on source country health indicators among migrants.

In an age where there is not only increasing migration to the UK but also increasing diversity of migrants based not just on countries and regions of origin but also reasons for migration and (changing) immigration status in the UK, the currently prevailing gap in collecting information from all categories of migrants in populationbased health surveys needs to be addressed. There is widespread local evidence that pregnant women, new mothers and their infants form a significant risk category among undocumented migrants and failed asylum seekers whose rights to free healthcare are constantly under threat from changes in government charging policies for overseas visitors (McLeish, 2002; Medact, 2007). It is important that research on experiences and needs of such vulnerable migrants who have a high degree of dependence on health services at their particular life cycle stage, be conducted if we are to fully understand patterns of and factors underlying health and healthcare among migrants as a whole.

Our research showing poorer health and use of care among migrant mothers mediated by socio-economic factors, thus supports the recommendations of the most recent CEMD report, and of organisations campaigning for the rights of vulnerable migrants, that the health status and access to care of pregnant migrant women need careful monitoring (Lewis, 2007; Medact, 2007; Medecins du Monde, 2007). However, the CEMD report also identified Black Caribbean mothers, who are less likely to be recent migrants, as having nearly four times the risk of death as White women. Given our evidence that ethnicity coupled with socio-economic circumstances are factors for poor health and healthcare use among mothers in some minority ethnic groups even after adjustment for country of birth or length of residence, we support the recommendations of the CEMD report and other bodies (Healthcare Commission, 2008) that difficulties associated with accessing and using care among broader groups of vulnerable 
mothers - such as a substantial proportion of Pakistani and Bangladeshi mothers in the MCS sample, whether UK born or not and whether recent migrants or established residents - should be acknowledged and addressed. Our findings thus support the wider focus on understanding and addressing cross-cutting social determinants of health, as they relate to health service objectives and in the development of a national health inequalities strategy (Health Inequalities Unit, 2008; Marmot et al., 2010) and suggest the importance of extending this to a broader minority ethnic population, whose health experiences and needs might not be sufficiently captured within current policy and practice.

\section{Acknowledgements}

We are grateful to Christine Hockley and to Claire Carson for valuable advice on data analysis; to Sarah Spencer for helpful comments on an earlier draft of the paper; and to Vanessa Hughes for checking data and referencing.

\section{References}

Abraldo-Lanza, A. F., Armbrister, A. N., Florez, K. R., \& Aguirre, A. N. (2006). Toward a theory-driven model of acculturation in public health research. American Journal of Public Health, 96(8), 1342-1346.

Acheson, D. (1998). Independent inquiry into inequalities in health report. London: The Stationary Office.

Chandola, T., \& Jenkinson, C. (2000). Validating self-rated health in different ethnic groups. Ethnicity \& Health, 5(2), 151-159.

Commission for Healthcare Audit and Inspection. (2008). Count me in 2008: Results of the 2008 national census of inpatients in mental health and learning disability services in England and Wales. Commission for Healthcare Audit and Inspection.

Department of Health. (2008). NHS: A guide to immunisations up to 13 months of age. London: Department of Health.

Dex, S., \& Joshi, H. (Eds.). (2005). Children of the 21st century: From birth to nine months. Bristol: The Policy Press.

Fitzpatrick, J., Jacobson, B., \& Aspinal, P. (2005). Indications of public health in the English regions, 4: Ethnicity and health. Association of Public Health Observatories.

Hansen, K. (Ed.). (2008). Millennium Cohort Study first, second and third surveys: A guide to the datasets ( $3 \mathrm{rd}$ ed.). London: Centre for Longitudinal Studies, Institute of Education, University of London.

Harley, K., \& Eskenazi, B. (2006). Time in the United States, social support and health behaviors during pregnancy among women of Mexican descent. Social Science E' Medicine, 62(12), 3048-3061.

Hawkins, S. S., Lamb, K., Cole, T. J., Law, C., \& The Millenium Cohort Study Child Health Group. (2008). Influence of moving to the UK on maternal health behaviours: prospective cohort study. BMJ, 336(7652), 1052-1055.

Health Inequalities Unit. (2008). Tackling health inequalities in the health report. London: Health Inequalities Unit Department of Health.

Health Protection Agency. (2006). Migrant Health. Infectious diseases in non-UK born populations in England, Wales and Northern Ireland. A baseline report. London: Health Protection Agency.

Healthcare Commission. (2008). Towards better births: A review of maternity services in England. London: Commission for Healthcare Audit and Inspection.

Hockley, C., Quigley, M., Johnson, J., Rosenberg, R., Dezateux, C., \& Joshi, H. (2007). Millenium cohort study: Birth registration and hospital episode statistics linkage. A guide to the dataset February 2007. London: Centre for Longitudinal Studies, Institute of Education, University of London.

Hunt, L. M., Schneider, S., \& Comer, B. (2004). Should "acculturation" be a variable in health research? A critical review of research on US Hispanics. Social Science $\mathcal{E}$ Medicine, 59(5), 973-986.

Idler, E., \& Benyamini, Y. (1997). Self rated health and mortality: a review of twentyseven community studies. Journal of Health and Social Behaviour, 38(1), 21-37.

Jayaweera, H., D'Souza, L., \& Garcia, J. (2005). A local study of childbearing Bangladeshi women in the UK. Midwifery, 21(1), 84-95.

Jayaweera, H., Joshi, H., Macfarlane, A., Hawkes, D., \& Butler, N. (2005). Pregnancy and childbirth. In S. Dex, \& H. Joshi (Eds.), Children of the 21st century. Bristol: Policy Press.

Johnson, M. (2006). Integration of new migrants. In S. Spencer (Ed.), Refugees and other new migrants: A review of the evidence on successful approaches to integration. London: Home Office.

Katbamna, S. (2000). 'Race' and childbirth. Buckingham: Open University Press.

Kelly, Y., Bartley, M., Schoon, I., \& Hope, S. (2004). Parents' health. In S. Dex, \& H. Joshi (Eds.), Millennium cohort study: First survey. A user's guide to initial findings. London: Centre on Longitudinal Studies, Institute of Education, University of London.

Knight, M., Kurinczuk, J., Spark, P., \& Brocklehurst, P. (2009). Inequalities in maternal health: national cohort study of ethnic variation in severe maternal morbidities. BMJ, 338, b542.

Seventh report on confidential enquiries into maternal deaths in the United Kingdom. In Lewis, G. (Ed.), The confidential enquiry into maternal and child health (CEMACH), saving mothers' lives: Reviewing maternal deaths to make motherhood safer 2003-2005. London: CEMACH.

Marmot, M., Allen, J., Goldblatt, P., Boyce, T., McNeish, D., Grady, M., et al. (2010). Fair society, healthy lives: The Marmot review.

McLeish. J. (2002). Mothers in exile: Maternity experiences of asylum seekers in England. Maternity Alliance.

Medact. (2007). Submission to the Kinds Fund inquiry into the safety of maternity services in England. London: Medact.

Medecins du Monde. (2007). Project London: Report and recommendations. London: Medecins du Monde UK.

Office for National Statistics. (2009). Migration statistics 2008: Annual report. Newport: Office for National Statistics.

Piachaud, D., Bennett, F., Nazroo, J., \& Popay, J. (2009). Social inclusion and social mobility. Report of task group 9. Marmot review: First phase report. London: Department of Health.

Plewis, I. (Ed.). (2007). The Millenium Cohort Study: Technical report on sampling (4th ed.). London: Centre for Longitudinal Studies.

Pollock, W., \& King, J. (2009). Inequalities in maternal health: routine collection of more detailed data is key to improving knowledge. BMJ, 338, b357.

Redshaw, M., Rowe, R., Hockley, C., \& Brocklehurst, P. (2007). Recorded delivery: A national survey of women's experience of maternity care 2006. Oxford: National Perinatal Epidemiology Unit.

Richardson, A., \& Mmata, C. (2007). NHS maternity statistics, England: 2006-06. The NHS Information Centre.

Sacker, A., Quigley, M., \& Kelly, Y. (2006). Breastfeeding and developmental delay findings from the Millennium Cohort Study. Pediatrics, 118(3), e682-e689.

Spencer, S., \& Cooper, B. (2006). Social integration of migrants in Europe: A review of the European literature 2000-2006. OECD.

Sproston, K., \& Mindell, J. (Eds.). (2006). Health Survey for England: The health of minority ethnic groups. London: The Information Centre.

Walsh, R., Redman, S., \& Adamson, L. (1996). The accuracy of self-report of smoking status in pregnant women. Addictive Behaviours, 21(5), 675-679.

Warburton, R. (2008). Turning evidence into action - Ethnicity data. Editorial Specialist Library for Ethnicity and Health Knowledge Weeks.

Zaman, M. J. S., \& Mangtani, P. (2007). Changing disease patterns in South Asians in the UK. Journal of the Royal Society of Medicine, 100(6), 254-255. 